\title{
PLEOMORPHIC SARCOMA OF THIGH WITH LONG SURVIVAL
}

\author{
BY \\ D. F. CAPPELL AND J. M. JOHNSTONE* \\ From the Department of Pathology, the University, and the Western Infirmary, Glasgow
}

(RECEIVED FOR PUbLICATION AUGUST 17, 1957)

In general it is fairly true to say that the prognosis in anaplastic malignant tumours of the soft tissues of the skeletal muscles is poor, but surprising exceptions do occasionally occur. The following two cases are examples of such exceptions and are reported because of their unexpected, long, and recurrence-free survival after local excision only. Both were rapidly growing, highly anaplastic tumours, of bizarre histological type, and thus were given a poor prognosis when first encountered.

\section{Case Reports}

Case 1.-In July, 1945, this 39-year-old turner complained of pain and an enlarging swelling, for seven weeks, in the antero-lateral aspect of the left thigh. The swelling was tender, fluctuant, and pulsatile, and the overlying skin was hot and reddened. The only other abnormal findings were a raised E.S.R. and slight pyrexia.

Blood only was obtained when the swelling was needled. At subsequent biopsy an unencapsulated, soft, and very vascular growth was found, with invasion of adjacent muscles. In August, 1945, the tumour was widely excised, most of the quadriceps apparatus and tensor fasciae latae being removed. Hypertrophy of residual muscles and recovery of function have been remarkable and no evidence of local or distant recurrence is apparent over 12 years after excision.

Case 2.-In May, 1948, a soft, ill-defined, and tender swelling was found in the right adductor magnus of this 44-year-old man. Pain, the presenting symptom, had been noticed for only two weeks, and at first the lump was thought to be a haematoma, there being no other abnormal feature. He was referred for physiotherapy but defaulted when the pain was quickly relieved.

Two months later he returned, the pain having recurred and the swelling now being double the previous size, firmer, and better defined. At biopsy a tumour was found lying deeply between the hamstring and the adductor groups of muscles in the upper third of the thigh. It was excised as widely

\footnotetext{
* Present address: General Hospital, Grimsby.
}

as possible in July, 1948. The tumour measured $15 \times 7 \times 7 \mathrm{~cm}$. and was coarsely lobulated, soft, and vascular, with areas of haemorrhage and necrosis, and could be separated from the surrounding muscle bundles. While as much muscle as possible was removed, clearance on the deep surface was less than $1 \mathrm{~cm}$. where the tumour had extended close to the femur.

Recovery of functional ability has been excellent and the patient remains free of tumour more than nine years after its removal.

\section{Histology}

The histological features of the two tumours were similar. They were highly cellular and largely formed of interlacing bundles of spindle cells, sometimes rather fibrillary, with eosinophilic, finely granular or vacuolated cytoplasm. The nuclei were plump, oval, and vesicular and usually contained a prominent nucleolus: two or more nuclei per cell, often arranged tandem fashion, were common. Reticulin and fibrous stromal tissue were relatively scant. In Case 2 many small round cells with scant cytoplasm were intimately mixed with the spindle cells and there were extensive areas of necrosis and haemorrhage.

A striking feature of both growths was the presence among the spindle cells of large numbers of bizarre and multinucleated giant cells (Fig. 1) which, in some areas, were so numerous as to form the predominant cell type. These giant cells generally ranged from 30 to $90 \mu$ in diameter, but others were much larger and measured as much as $200 \mu$ in diameter. Their cytoplasm was eosinophilic, with fine to coarse granularity, or, less commonly, vacuolation. The nuclei were rounded, of variable size and number, vesicular to hyperchromatic, and generally contained a prominent nucleolus. They were obviously enormously polyploid, but often the nuclear chromatin was fused into a single irregular mass.

Normal and aberrant multipolar mitotic forms were common in both the spindle cells and giant 


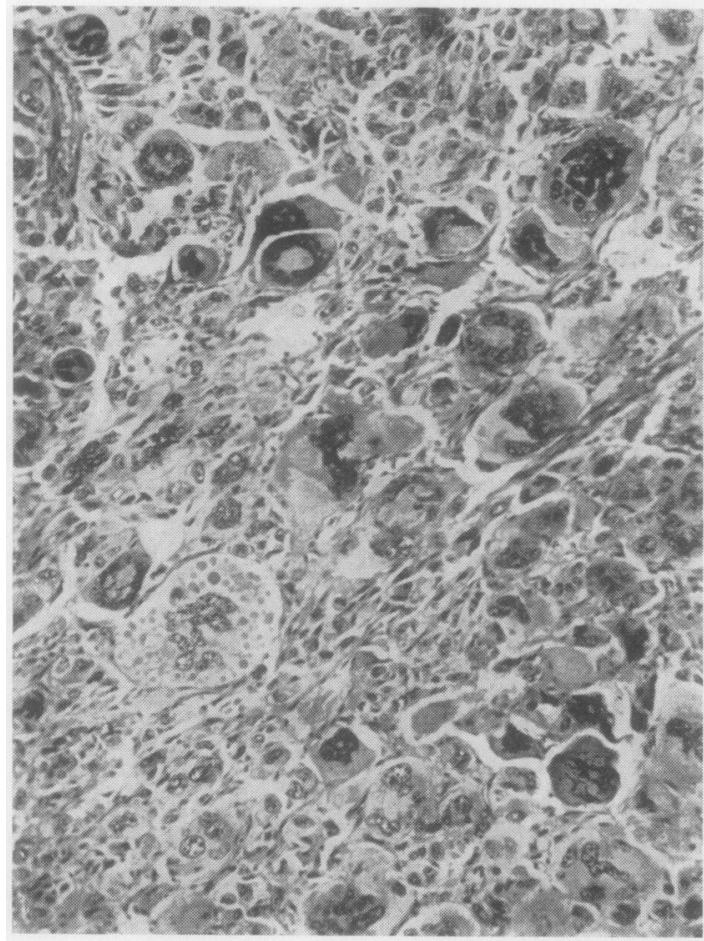

(a)

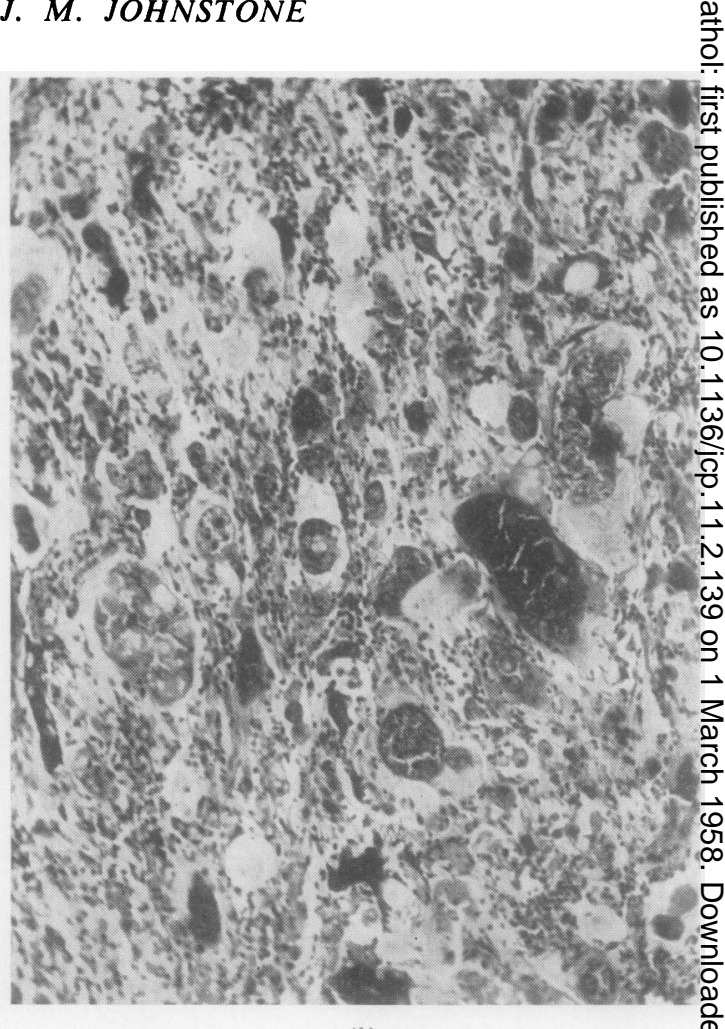

(b)

Fig. 1.-(a) Case 1 and $(b)$ Case 2 : representative fields with many bizarre giant cells. In some areas the giant cells were even more numerous than here. Haematoxylin and eosin, $\times 110$.

cells. While occasional large cells resembling myoblasts were present, racquet cells, strap cells, and sharply angulated cells were uncommon.

Both tumours showed extreme pleomorphism and morphologically they closely resembled rhabdomyosarcoma, but the failure to demonstrate cross striations prevented such a diagnosis being made with certainty.

\section{Discussion}

These cases are examples of anaplastic and pleomorphic neoplasms. The patients, while originally thought to have a poor prognosis, have unexpectedly survived and are remarkably well, with no recurrence, after long periods.

The failure to demonstrate cross striations leaves the precise nature of the growths in some doubt, but their general appearances are those of rhabdomyosarcoma. Some authors, such as Willis (1953) and Constance (1955), insist on the presence of cross striations before accepting any tumour as of striped muscle origin and tend to place pleomorphic growths such as these in the fibrosarcoma group. It is of interest, however, that in a case described by Lendrum (1947) no. striations were demonstrated in the primary diaphragmatic tumour but they were clearly seen:in the metastases.

Others do not require such rigid criteria for the diagnosis of rhabdomyosarcoma. Purdy Stouts (1946, 1948, 1953), for example, excludes the pos-o sibility of this type of growth being a fibrosarcoma and believes that the presence of manyo bizarre giant cells indicates a derivation from. other specialized cells such as rhabdomyoblasts. His series of 121 cases of rhabdomyosarcoma of skeletal muscle (1946) included examples showing no more precise features of striped muscle origin than do the two in question.

Whatever name is applied to these anaplastic growths, be it rhabdomyosarcoma, fibrosarcoma or merely pleomorphic sarcoma, there is genera ${ }_{0}$ agreement that the anaplasia and the bizarre gian 5 cells are indicative of a high degree of malignancy $\vec{\Phi}$ with a poor prognosis.

Nevertheless, in a few instances, long survival: even with persisting tumour, is recorded (Stout 1946). Certainly it does seem that this type of 
growth, with many giant cells, does sometimes fare rather better than those in which the predominant cells are small and rounded, as in some rhabdomyosarcomata. It may well be that the latter cell type is the more primitive, that it is the one which is more easily disseminated, and that it is from it that the giant cells are differentiated in the new implantation sites (Cappell and Montgomery, 1937 ; Cappell, 1948).

In any event, while a guarded prognosis must be given in pleomorphic tumours such as these, it is well to remember that long survival is sometimes possible, even without amputation, provided that surgical excision is adequate.

\section{Summary}

Two examples of pleomorphic and anaplastic tumours of the soft tissues of the thigh are described. While no cross striations were present they resembled rhabdomyosarcoma morphologically. The striking feature of each was the presence of numerous large and bizarre multinucleated giant cells.

Each patient was originally given a very poor prognosis, but they have survived, free of recurrence, for 12 and nine years respectively after local excision only.

We are grateful to Mr. R. Barnes and to Mr. R. A Jamieson for the clinical details of these patients.

\section{REFERENCES}

Cappell, D. F. (1948). Ann. roy. Coll. Surg. Engl., 2, 80. Cond Montgomery, G. L. (1937). J. Path. Bact., 44, 517 Constance, T. J. (1955). Ibid., 70, 365 .

Lendrum, A. C. (1947). Proc. path. Soc. Gt. Brit., Newcastle. Stout, A. P. (1946). Ann. Surg., 123, 447.

(1948). Cancer (N.Y.), 1,30 .

(1953). Tumors of the Soft Tissues. Atlas of Tumor Pathology: Sect. 11, Fascicle 5. Armed Forces Institute of Pathology, Washington.

Willis, R. A. (1953). Pathology of Tumours, 2nd ed. Butterworth, London. 